\title{
مكانة قضاء الإستعجال الإداري في قانون الإجراعات المدنية والإدارية
}

\author{
عبد النور سهام \\ كلية الحقوق \\ جامعة الإخوة منتوري قسنطينة

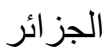

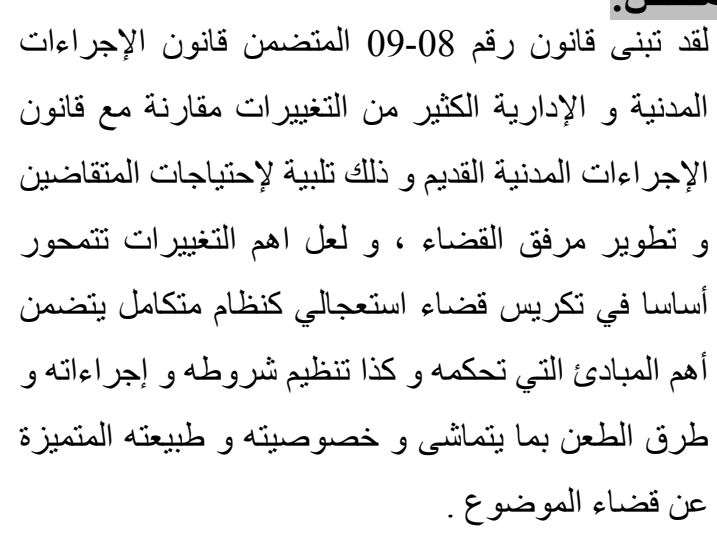

\section{مقدمة:}

لقد كرس دستور 1996 لأول

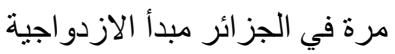
القضائية من خلال المادة 152، الأرداجية و لكن بقيت ازدو اجية مؤسسانية بدون روح حنى جاء قالانون الإجراءات الدانية و الإدارية ليضخ الراءت في القات القضاء

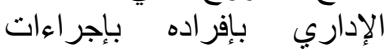
إدارية و هذا تكريسا لخصوصية الإنية

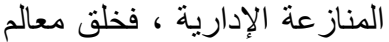
جديدة ومنميزة عن الإجراءة ألخات الدذنية ، تحاول أن تتماشىى و الإجرات

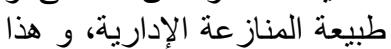
تكريسا لمبدأ ازدو اجية القضاء.

\begin{abstract}
:
Law No. 08-09, which contains the civil and administrative procedures law, adopted many changes compared to the old civil procedure law in order to meet the needs of the litigants and the development of the judiciary facility. The most important changes are mainly in devoting an emergency judiciary as an integrated system that includes the most important principles governing it. Such as the organization of its conditions and procedures and methods of appeal in line with its specificity and nature distinct from the issue
\end{abstract}




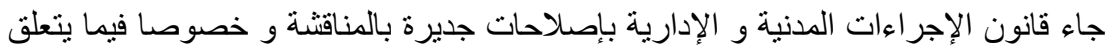

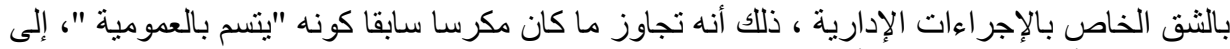

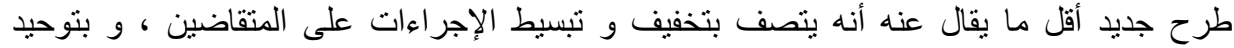

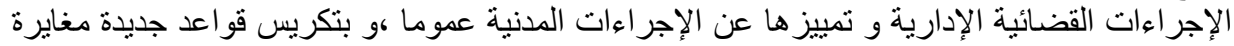

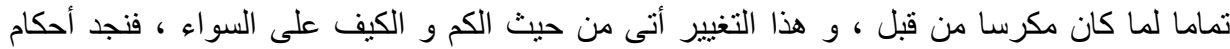

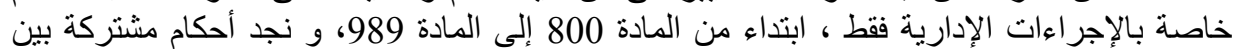

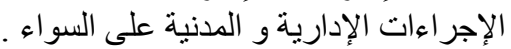

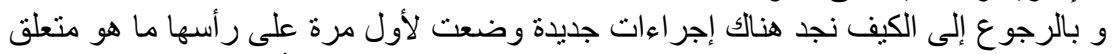

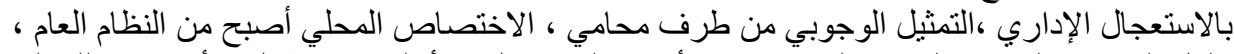

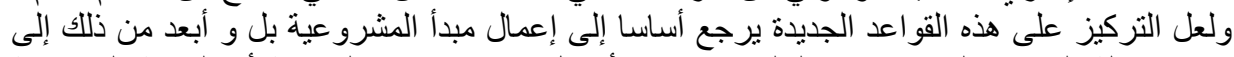
تجسيد دولة الحق و القانون ، و بالتالي إخضاع أعمال الإدارة سواء القانونية أو المادية إلى رقابة العابة القاضي .

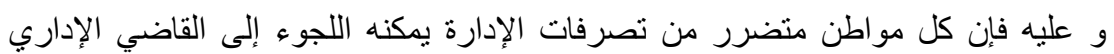

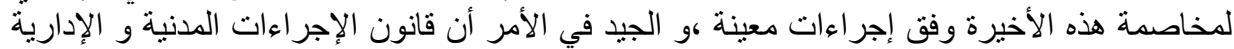

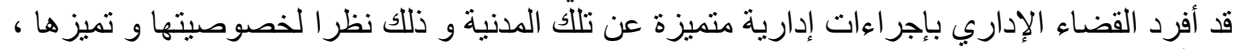

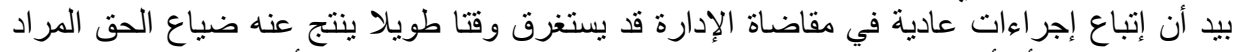

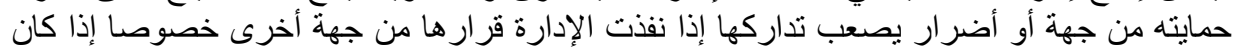

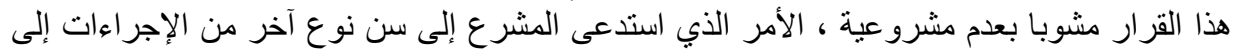

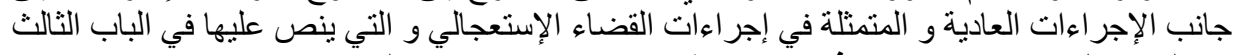

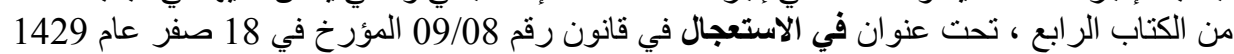

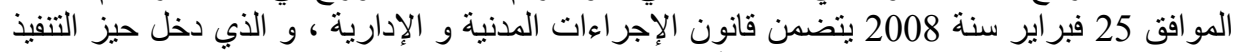

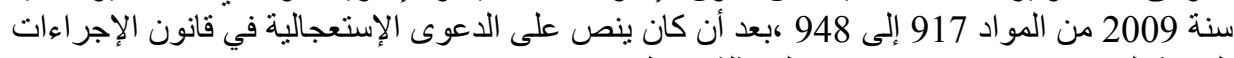

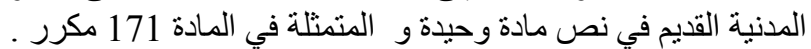

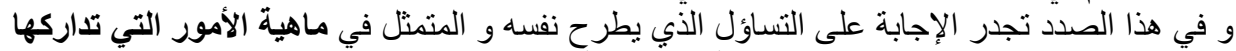

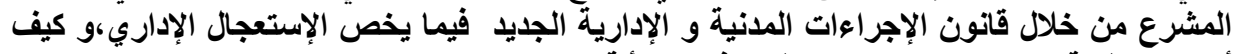

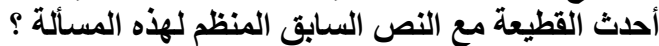
و من أجل الإجابة على هذا التساؤل ارتأينا تقسيم البحث إلى الى مبحثين :

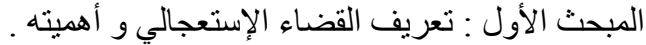

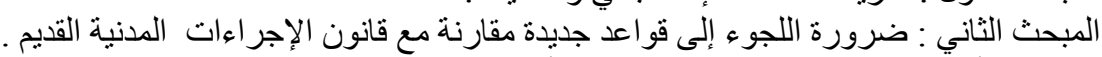
المبحث الأول : تعريف القضاء الإستعجالي و أهميته:

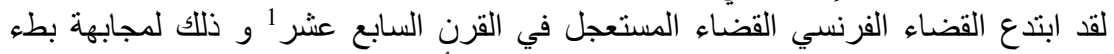

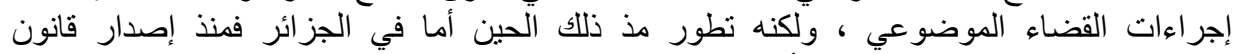

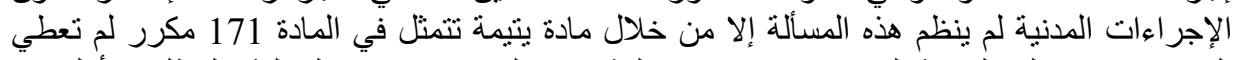

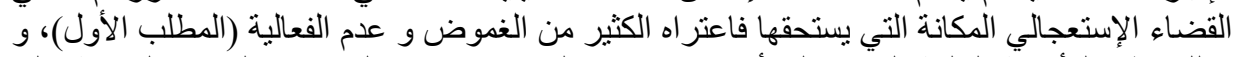

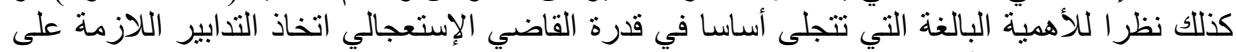

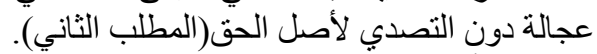
المطلب الأول : تعريف القضاء الإستعجالي:

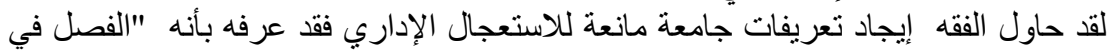

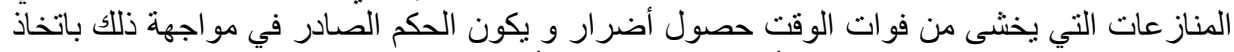

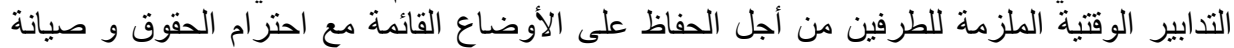

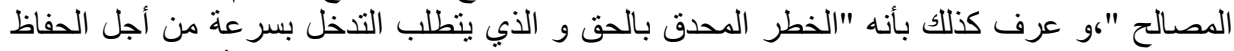
على هذا الحق مما يحتم تغيير المو اعيد و تسريع إجر اءات الفصل في هذه الدعاوي لأجل تفادي الضرد 


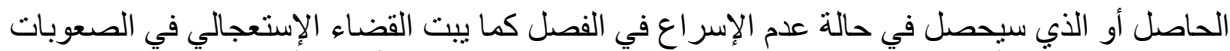

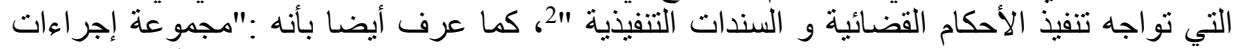

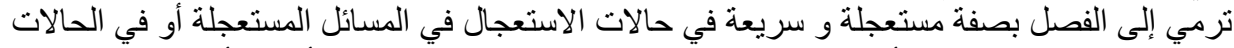

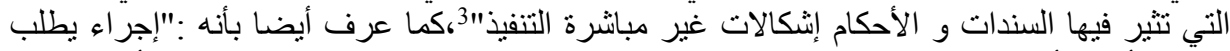

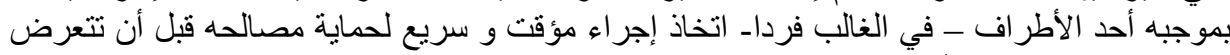

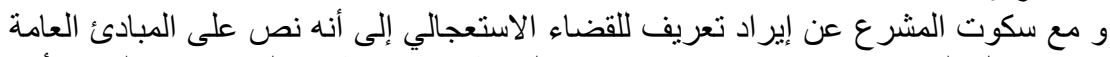

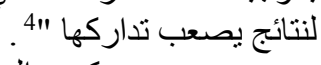

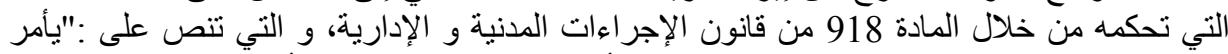

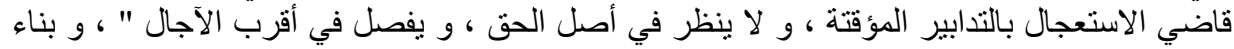

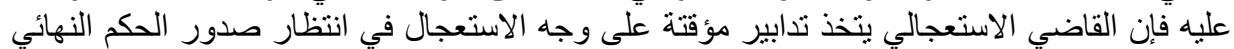

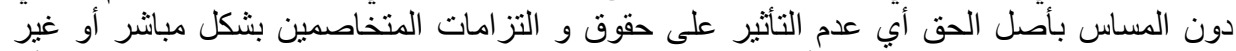

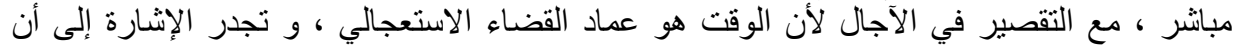
تقصير الآجال يشمل تقديم المذكرات و الرد عليها ، و كذا آجال التبليغ و الاستئناف .

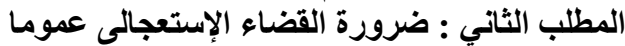
تظهر أهمية القضاء الإستعجالي عموما في نقاط كثيرة بمكن تلخيصاء الإسيتها كالآتي: تسهيل التقاضي للمو اطنين و تسهيل العمل القضائي.

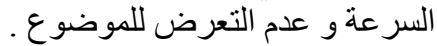

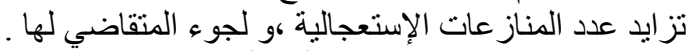

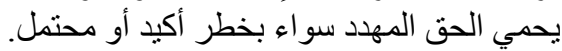

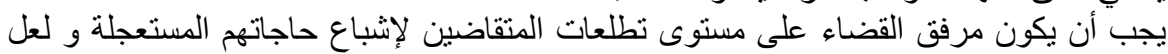

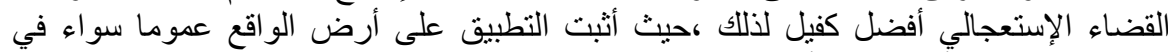

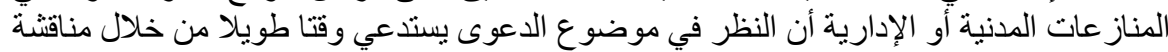

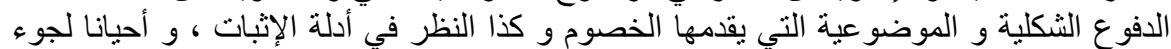

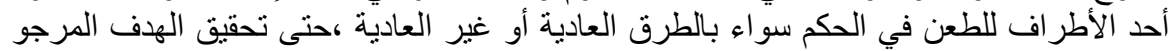

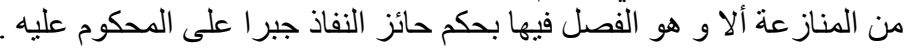

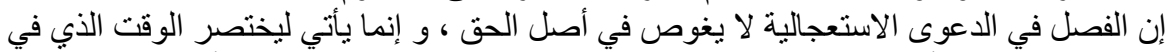

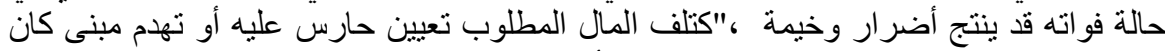
المطلوب سرعة ترميمه حفاظا له من السقوط أو موت شاهد كان المطلوب سر الهر عة سماع شهدنه

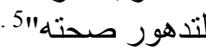
يساعد القضاء الاستعجالي على وقف تتفيذ قرارات إدارية مشوبة بعيب يجعلها قابلة للبطلان

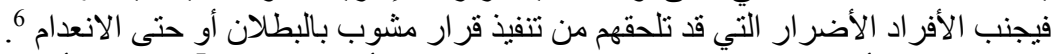

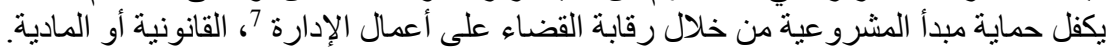

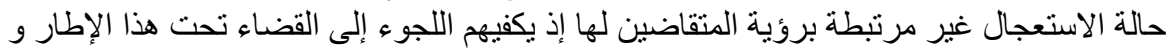

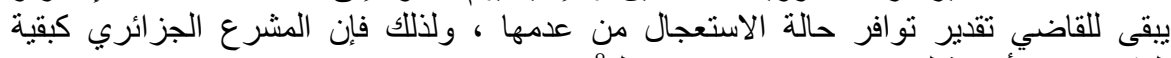

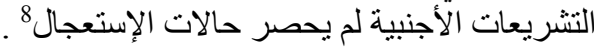
إن الطرف الثاني في الخصومة هو الإدارة صاحبة امتياز ات السلطة العبات العامة ، و و القاضي الإداري

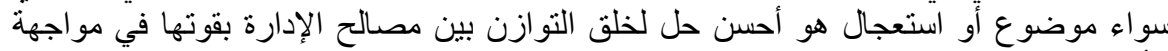

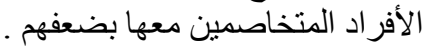

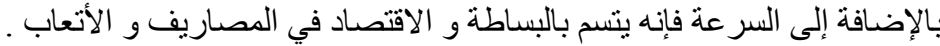

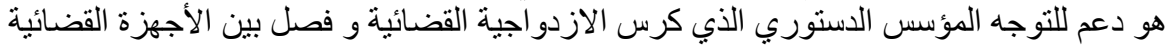

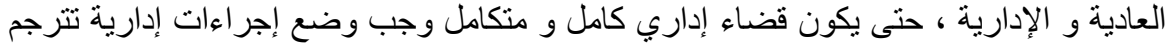


خصوصية الخصومة الإدارية ، وكذلك رفع اللبس و الغموض الذي اعترى الكثير من الدفاهيم التي

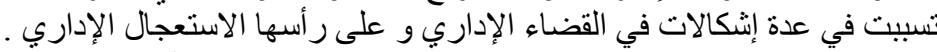

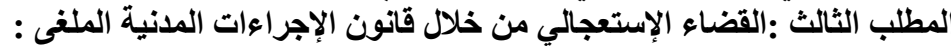

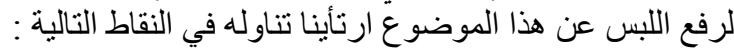

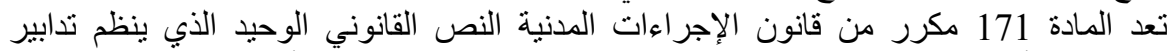

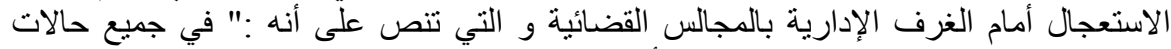

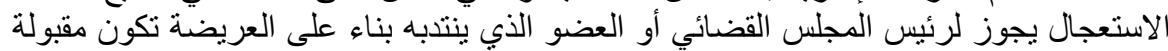

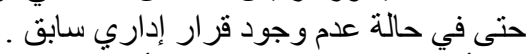
1-الأمز بتوجيه إنذار - سواء أكان مطلوبا أو غير مطلوب الرد عليه -بمعرفة أحد موظفي قلم

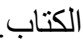

2-تعيين أحد موظفي قلم الكتاب أو أحد الخبراء ليقوم دون تأخير بإثبات الوقائع الحاصلة بدائرة

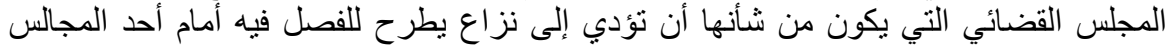

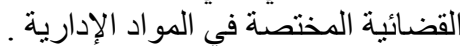

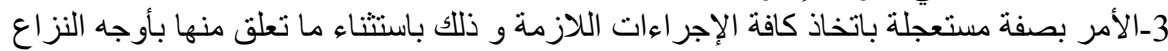

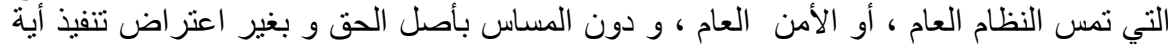

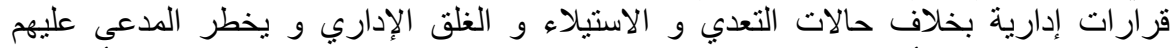

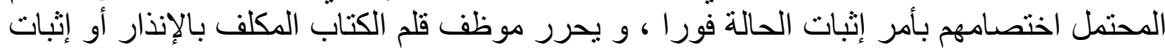

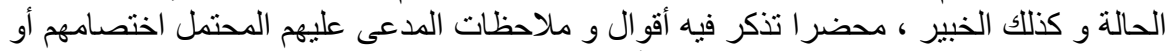

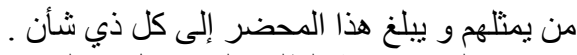

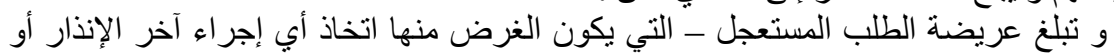

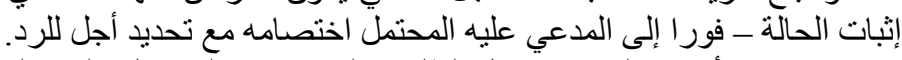

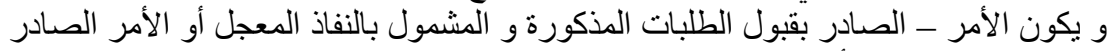

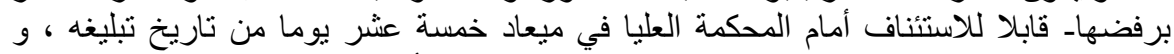

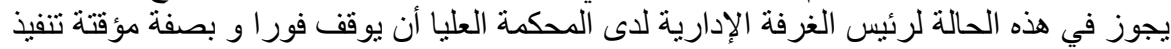

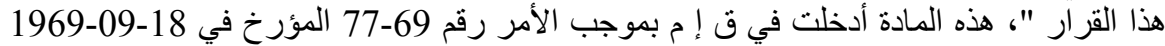

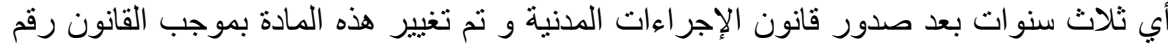

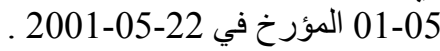

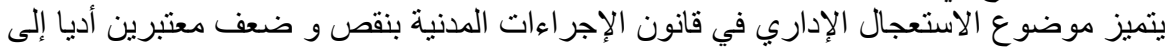

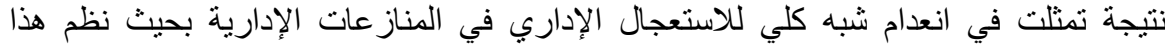

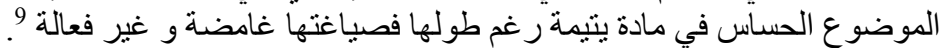

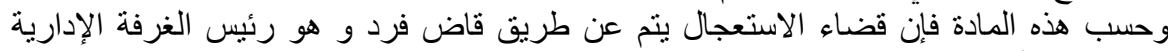

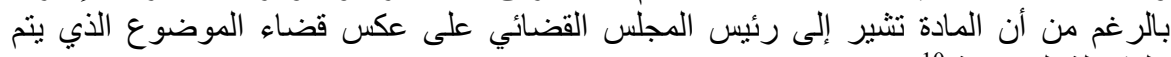

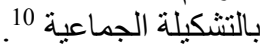

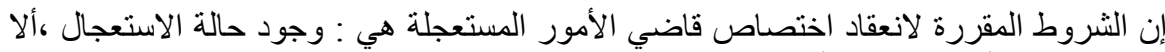

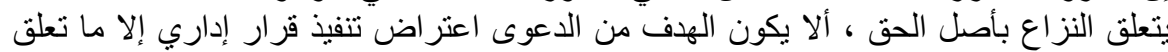

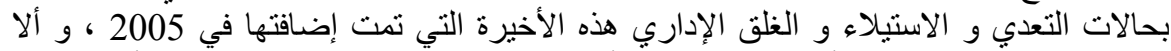

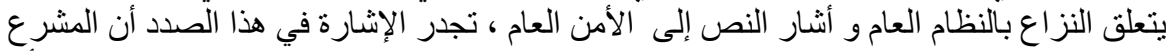

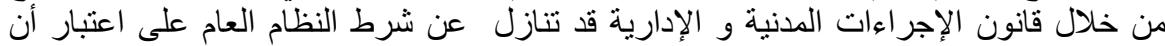

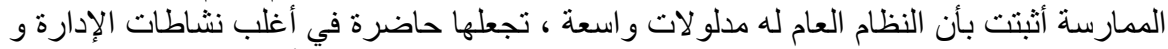

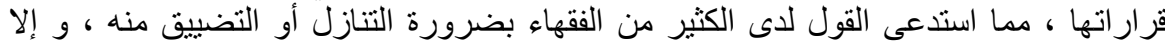

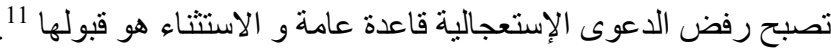


هناك شرطيين إضافيين قرر هما الاجتهاد القضائي و هما أن ترفع الدعوى في آجال معقولة ، و و أن

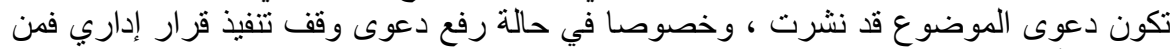

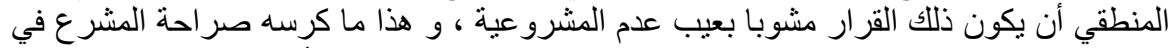

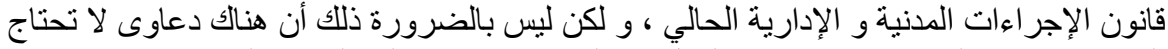

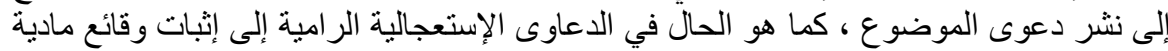

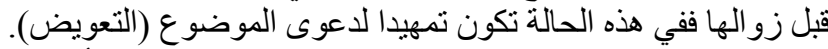

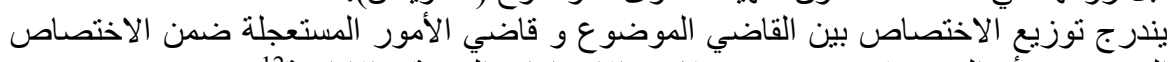

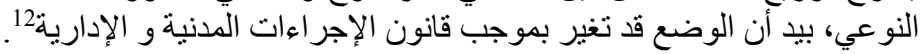

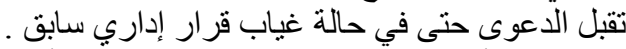

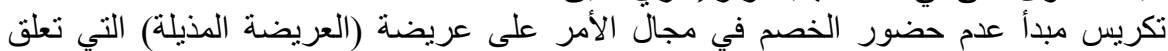

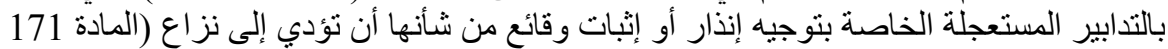

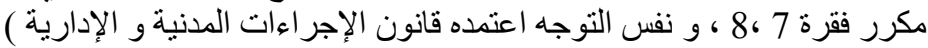

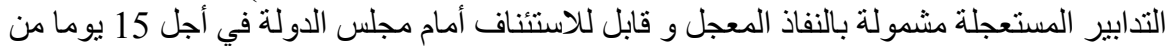

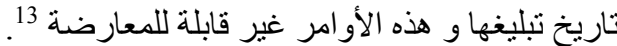

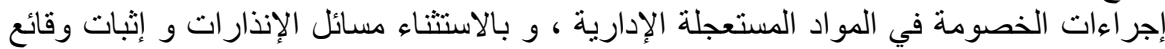

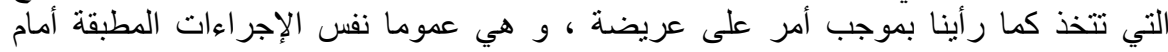

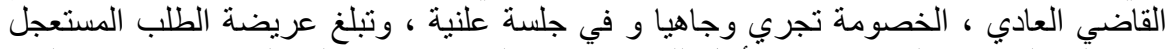

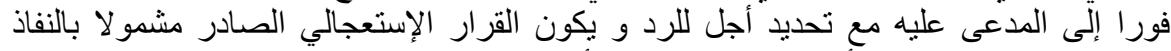

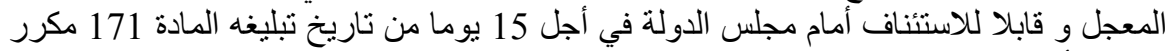

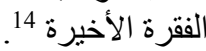
المبحث الثاني :ضرورة اللجوء إلى قواعد جديدة من خلال قانون الإجراءات المدنية و الإدارية الجديد مقارنة مع قانون الإجراءات المدنية السابق:

مقارنة مع قانون الإجراءات المدنية القديم وجب الإنداء التخلي عن القواعد المتعلقة بالاستعجال

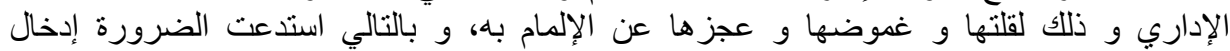

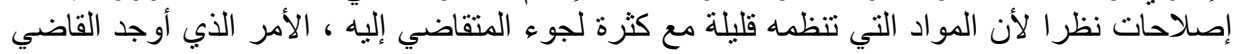

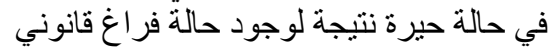

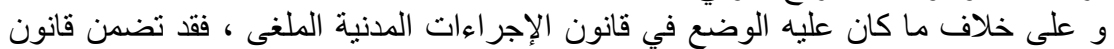

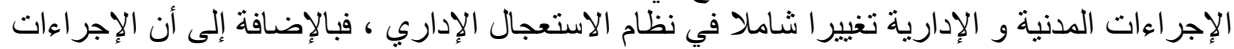

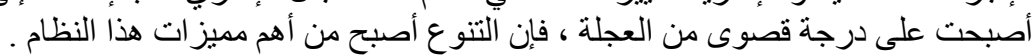

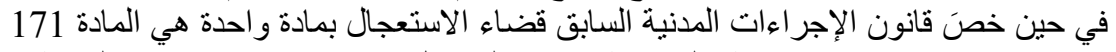
مكرر بموجب قانون رقم

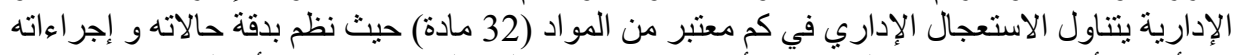

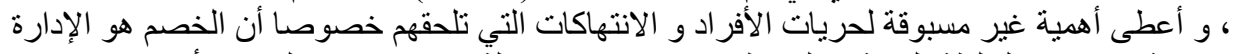

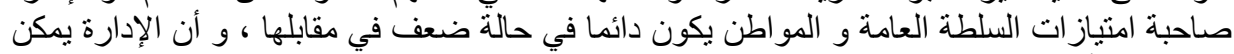

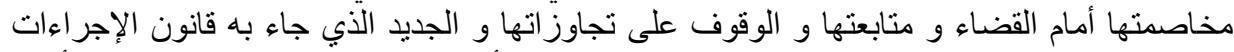

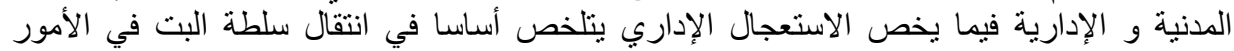

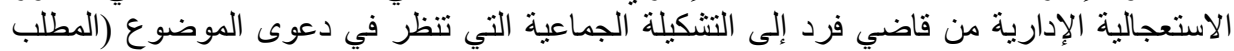

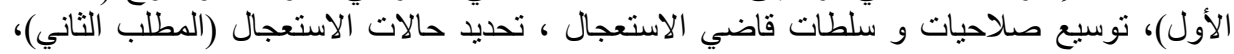
تحديد إجر اءات و شروط الإد الطعن في الدعوى الاستعجالية ، بمعنى آخر خلق نظام كامل قائم بذاته متعلق الأن

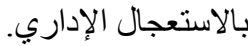
المطلب الأول : مبذأ التثكيلة الجماعية: 
على الر غم من طابع العجلة الذي يقتضيه القضاء الإستعجالي إلى أن المشرع ،قرر أن يفصل

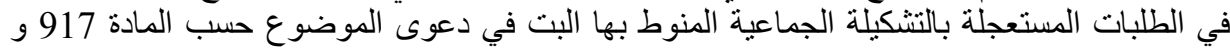

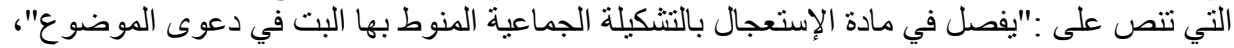

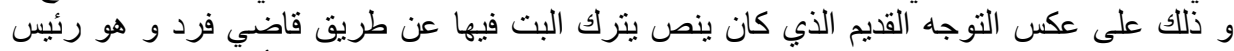

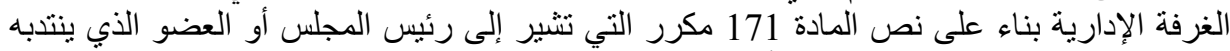

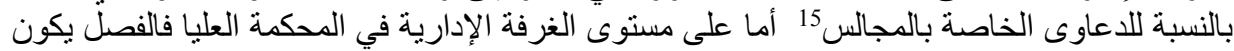

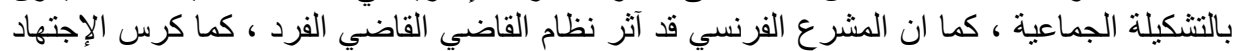

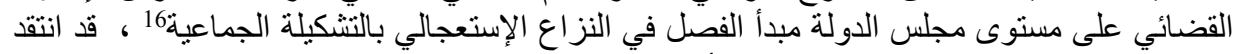

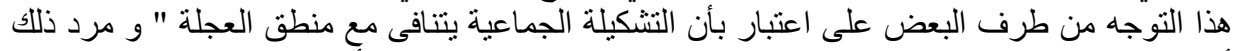

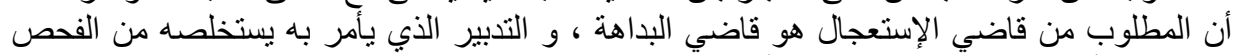

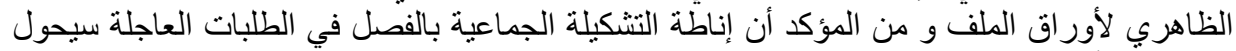

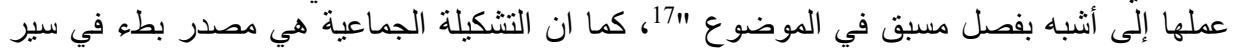

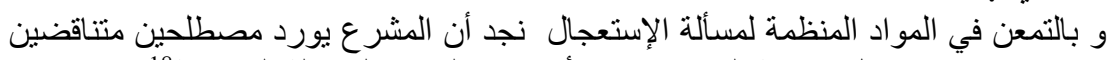
الخصومة القضائية التصنية

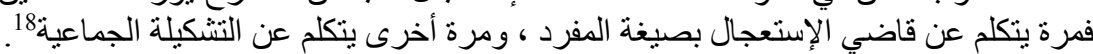

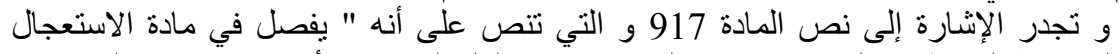

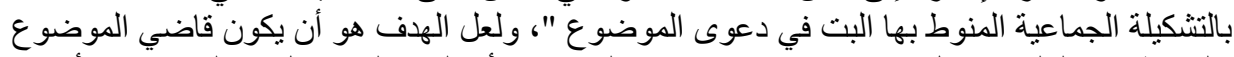

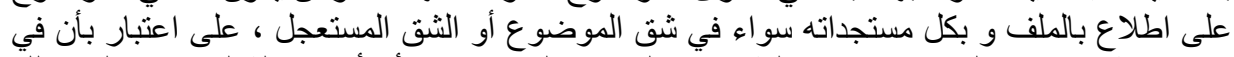

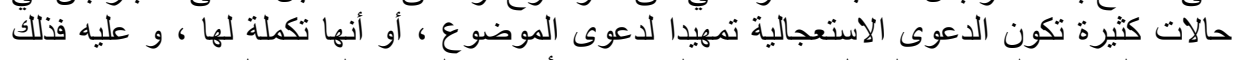

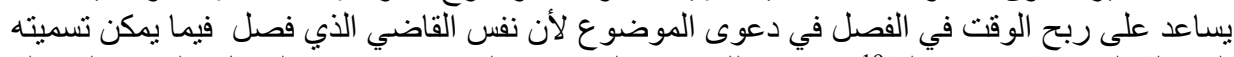

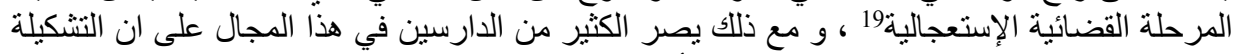

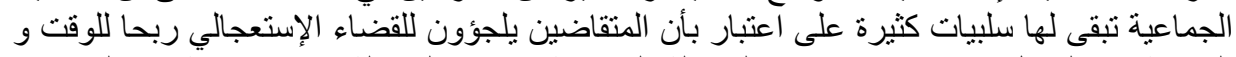

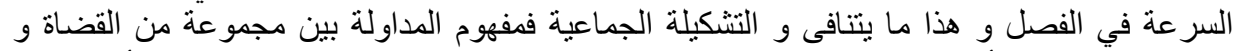

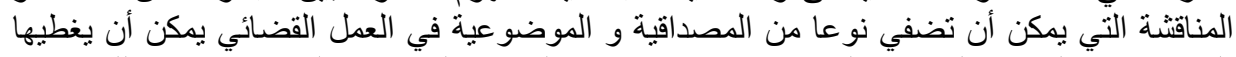

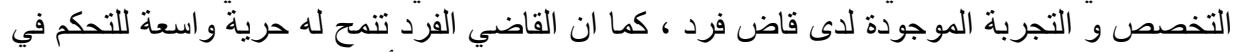

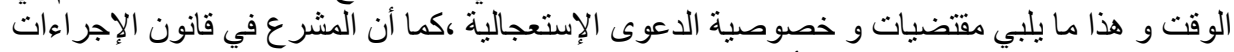

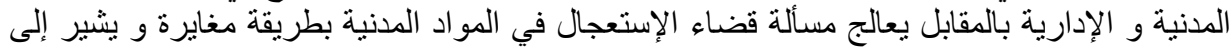

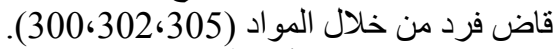
المطلب الثاني : تعدد أنظمة قضاء الاستعجال :

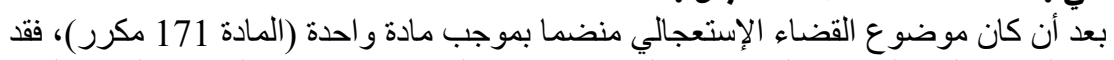

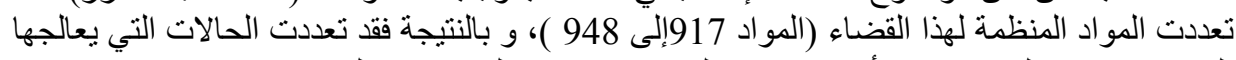

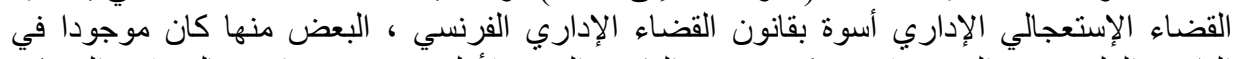

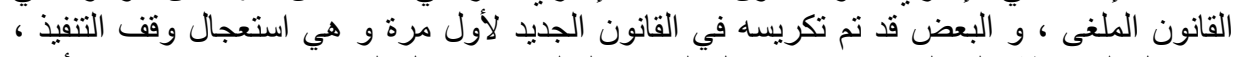

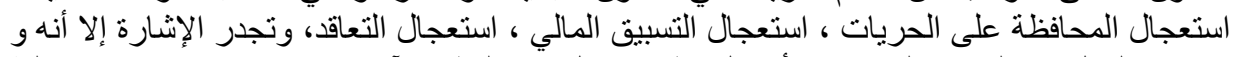

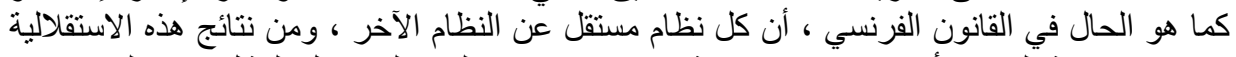

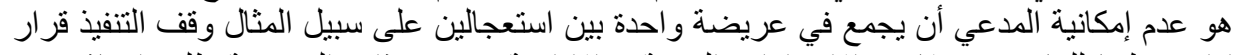

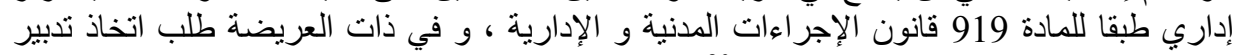

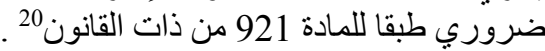
و مع أن المشرع في قانون الإجراءات المدنية و الإدارية أنى بأنظمة جديدة إلى أنه احتفظ بالأنظمة القديمة التي كانت مكرسة في قانون القديم. 
اولا : استعجال - وقف :

نصت المادة 919 على هذا النوع من الاستعجال و يعتبر من أهم أنو اعه ، و يقصد بله به إمكانية

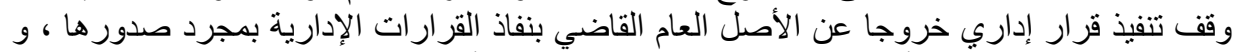

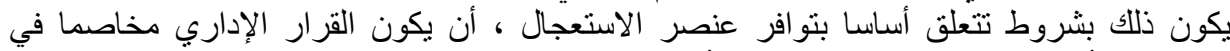

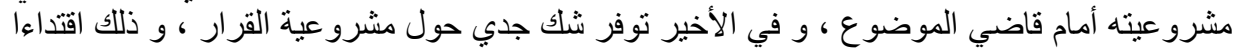

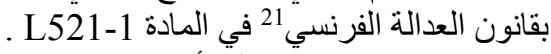

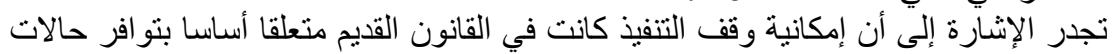

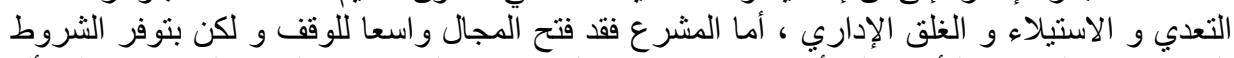

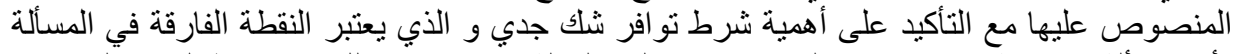

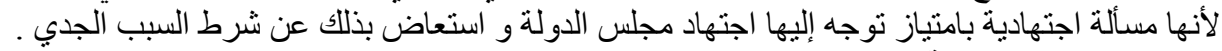
ثانيا : استعجال - الحرية : المانية

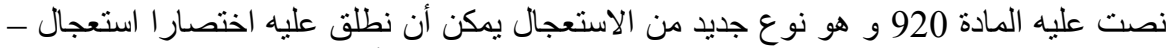

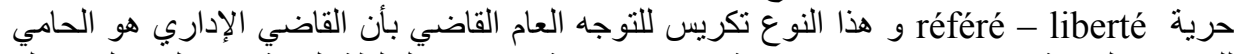

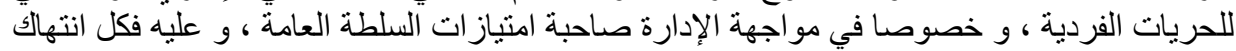

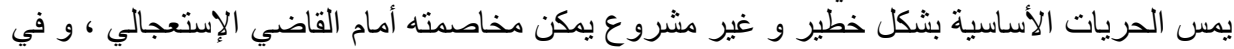

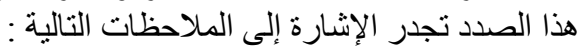

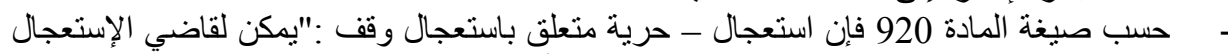

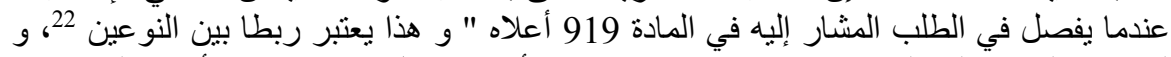

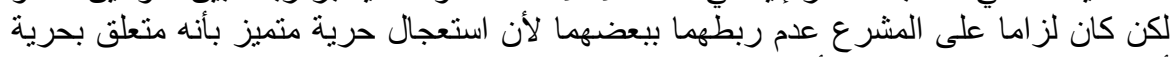

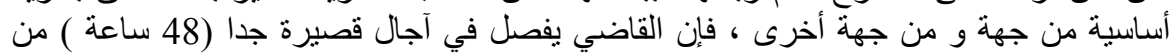

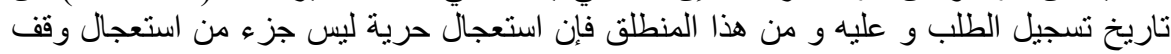

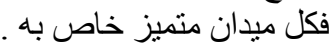
- أن المشرع لم يحدد الحريات الأساسية فترك بذلك المجال مفتوحا أمام تقدير القاضي الإستعجالي حسب مجريات و ظروف كل قضية .

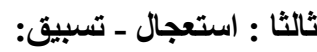

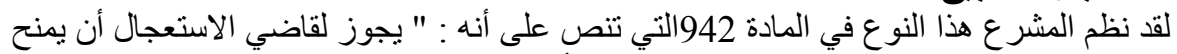

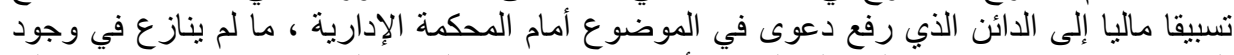

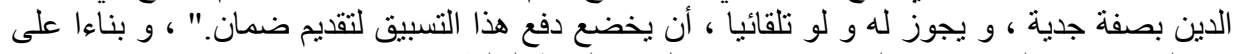

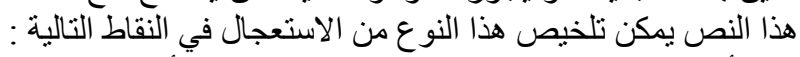

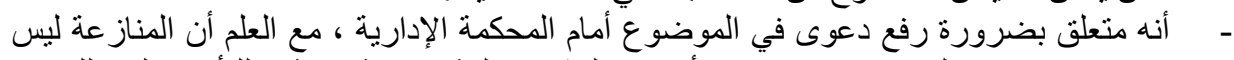

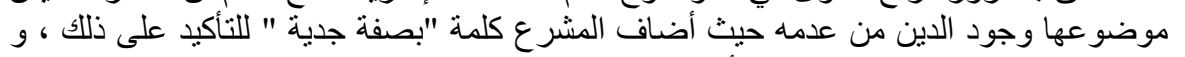

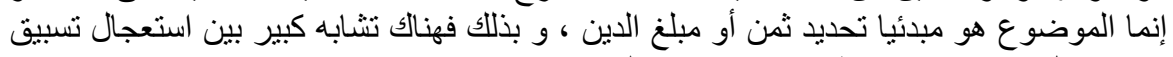

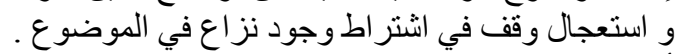

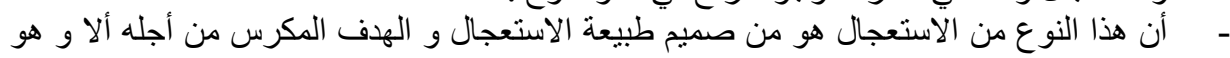

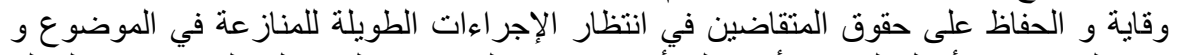

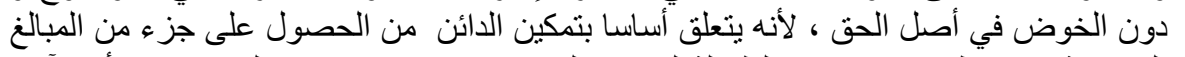

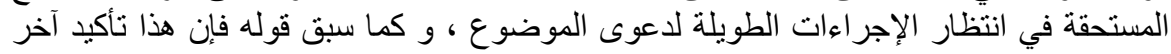

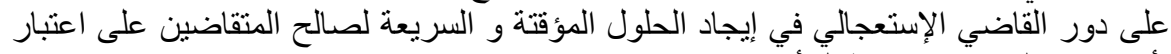

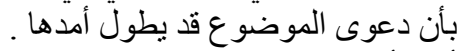
أن الأمر الصادر من المحكمة الإدارية يكون قابلاديلا للاستئناف أمام مجلس الدولة خلال 15 يوما من تاريخ التبليغ الرسمي و ذللك حسب المادة الادرية 943. 
رابعا : استعجال- التعاقد

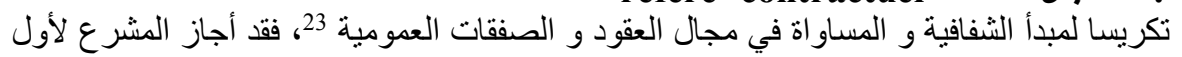

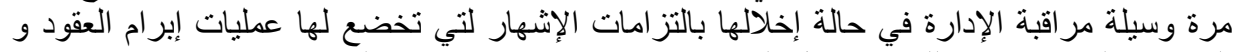

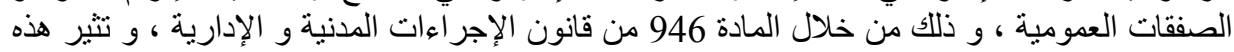

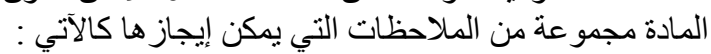

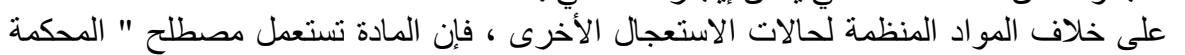

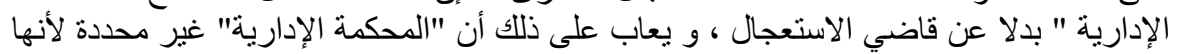

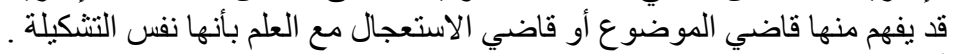

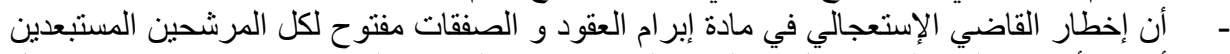

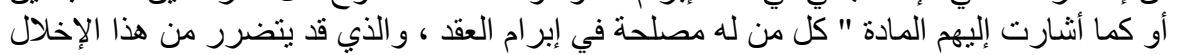

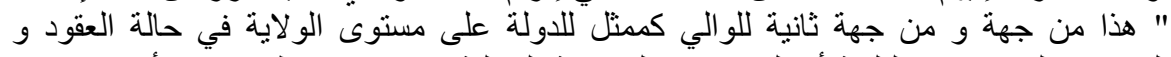

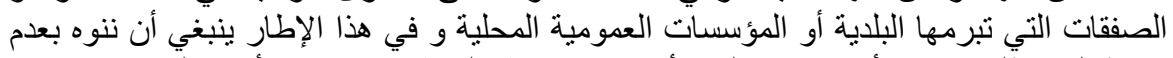

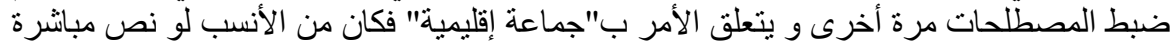
على "البلدية".

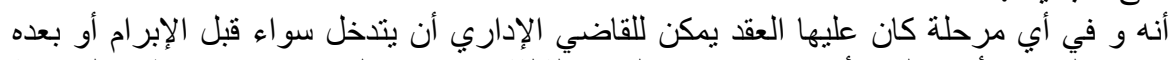

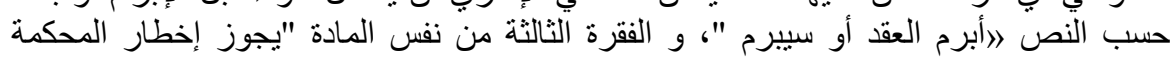

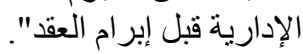

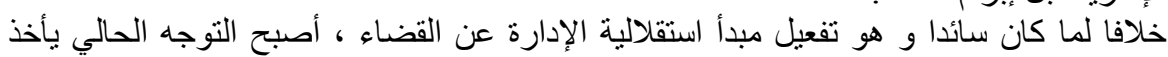

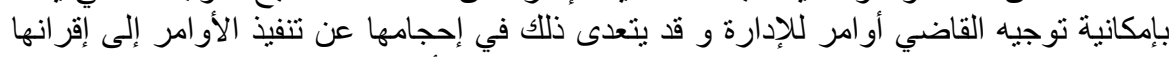

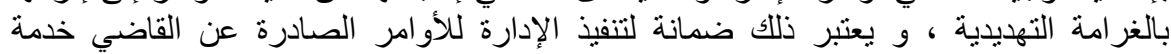

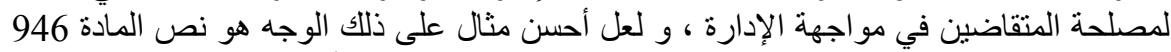

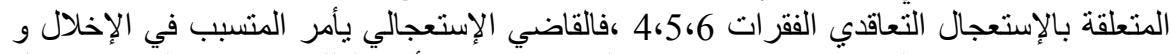

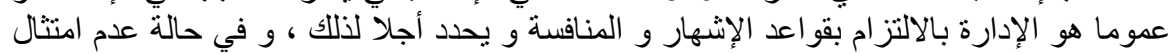

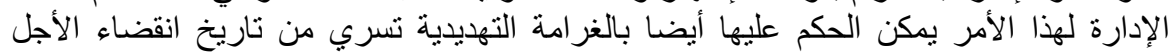

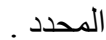

بل و ذهبت المادة إلى أبعد من ذلك في فقرتها 6 و الأخيرة إلى إمكانية القاضي الإستعجالي الأمر

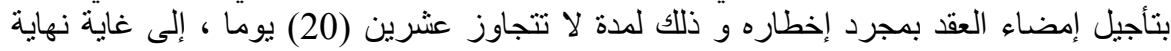

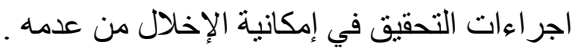

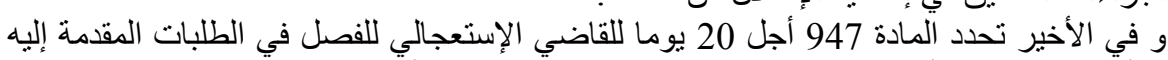

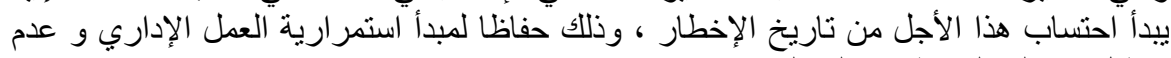

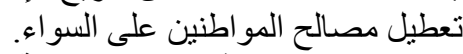
خامسا: الإستعجال في المادة الجبائية :

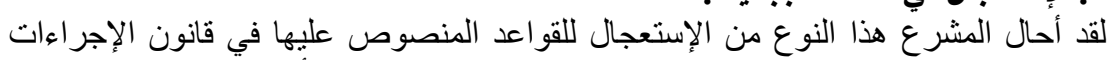

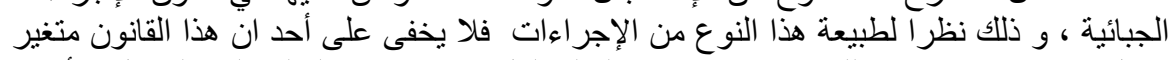

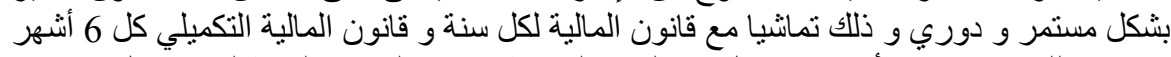

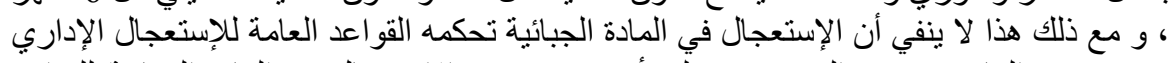

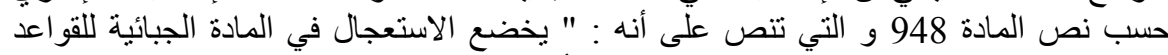

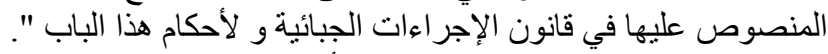

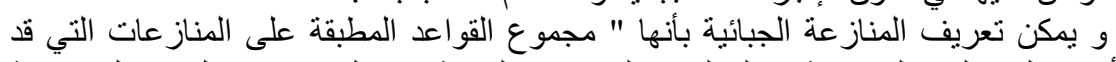

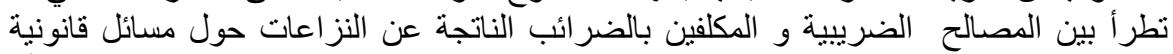

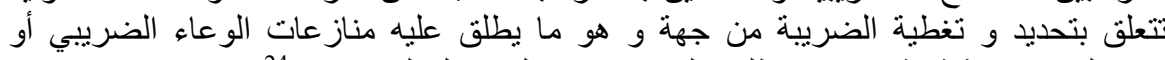

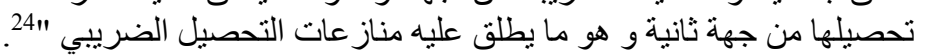




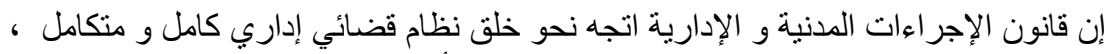

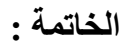

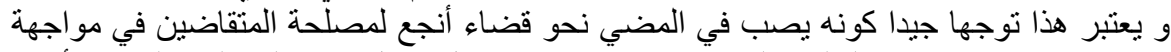

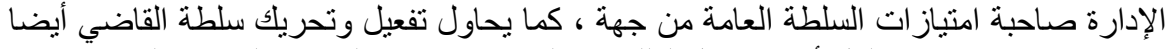

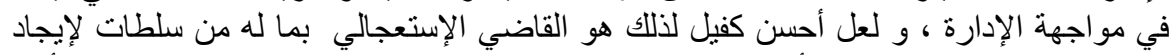

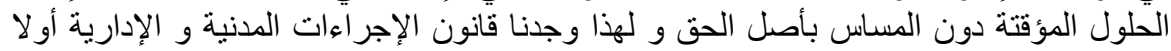

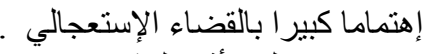

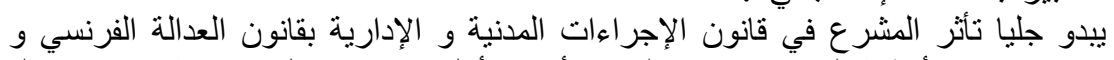

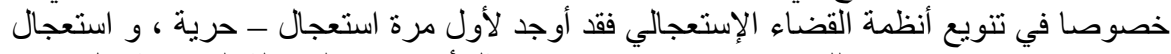

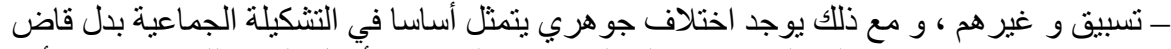

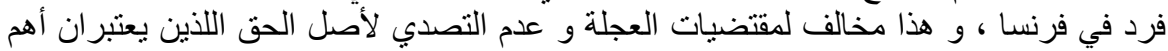
المبادئ التي يقوم عليها الإستعجال الإداري .

1) نبيل صقر، ،الوسيط في شرح قانون الإجر اءات المدنية و الإدارية ، الإجر اءات الإدارية ، دار

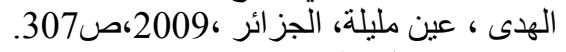

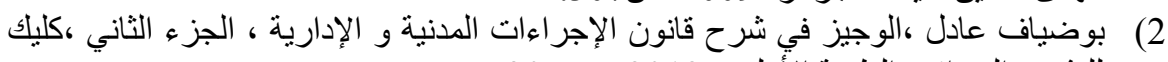

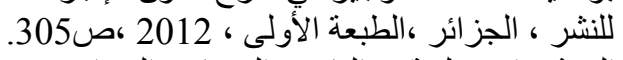

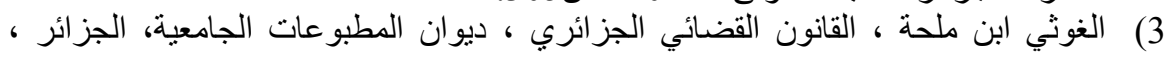

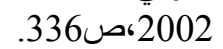

4) مسعود شيهوب ، المبادئ العامة للمنازعات الإدارية ،نظرية الإختصاص ،الجزء الثالث ،

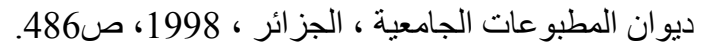

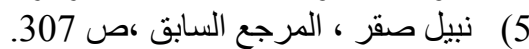

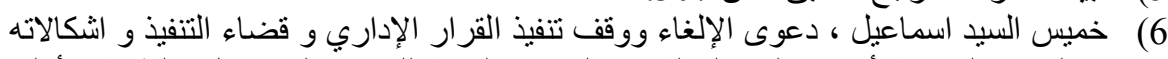
و الصيغ القانونية أمام مجلس الدولة مع المبادئ العامة للقضاء المستعجل ،الطبعة الأولى لئى 1761992،

7) بشير بلعيد،القضاء المستعل في الأمور الإدارية ،ديوان المطبوعات الجامعية ، الجزائر ،

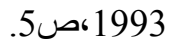

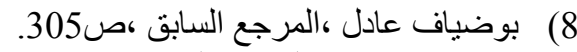

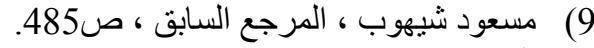

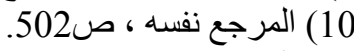

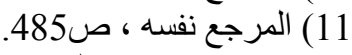

12) محمد بر اهيمي ،القضاء المستعجل ، الجزء الجهاء الأول ، ديوان المطبو عات الجامعية ، الجزائر ، الطبعة الثانية، 2007، 205،

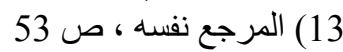

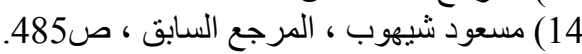

15) عدو عبد القادر ،الجديد في قضاء الإستعجال الإداري ، مجلة القانون و المجتمع ،العدد الأول

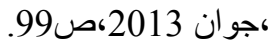

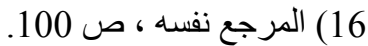
17) رشيد خلوفي ، قانون المناز عات الإدارية ،الجزء الثالث ،الطبعة الثانية، ديوان المطبوعات

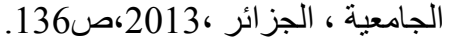

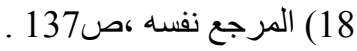


19) عدو عبد القادر ، المرجع السابق ،ص101.

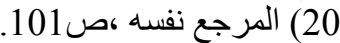

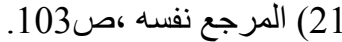

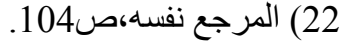

23) بوضياف عادل ، المرجع السابق ، ص328. 